\title{
Impact factors on intraocular pressure measurements in healthy subjects
}

\author{
T Theelen, C F M Meulendiiks, D E M Geurts, A van Leeuwen, N B M Voet, A F Deutman
}

Br J Ophthalmol 2004;88:1510-1511. doi: 10.1136/bjo.2004.049924

Aim: To evaluate whether intraocular pressure (IOP) calculation by applanation tonometry is determined more essentially by the subject's neck position or by neck constriction.

Methods: 23 right eyes of 23 healthy subjects (12 male, 11 female) were included. IOP was measured by applanation tonometry with the TonoPen on sitting participants under four different conditions: with open collar upright $(A)$ or with the head in the headrest of a slit lamp (B), with a tight necktie upright (C) or in slit lamp position (D). All measurements with neck constriction were performed 3 minutes after placing the necktie.

Results: Mean IOP was 16.9 (SD 2.3) mm Hg (range 11$21 \mathrm{~mm} \mathrm{Hg}$ ) (A), 18.1 (SD 2.2) $\mathrm{mm} \mathrm{Hg}$ (range 14$22 \mathrm{~mm} \mathrm{Hg}$ ) (B), 17.9 (SD 2.9) $\mathrm{mm} \mathrm{Hg}$ (range 12$25 \mathrm{~mm} \mathrm{Hg}$ ) (C) and 18.7 (SD 2.7) $\mathrm{mm} \mathrm{Hg}$ (range 13$24 \mathrm{~mm} \mathrm{Hg}$ ) (D). Mean IOP increased by 1.3 (SD 2.6) $\mathrm{mm} \mathrm{Hg}$ $(p=0.028$, paired $t$ test, range +0.2 to $+2.4 \mathrm{~mm} \mathrm{Hg}$ ) if subjects changed position from $A$ to $B$. There was no statistically significant difference between measurements with or without neck constriction.

Conclusion: Applanation tonometry may be inaccurate if performed in slit lamp position. In contrast, tight neckties do not significantly affect IOP evaluation in healthy subjects.

$\mathrm{E}$ evated intraocular pressure (IOP) is generally accepted as one of the primary risk factors for glaucoma. Accuracy of IOP measurement may be altered by several factors, such as breath holding, Valsalva manoeuvres, and tight collars. ${ }^{1}$ Goldmann applanation tonometry is the calculation method used most widely. However, recent studies suggested that IOP would not be calculated adequately if Goldmann tonometry was applied on thin corneas. ${ }^{2}$ Tonometry by a portable electronic device (TonoPen), which appears to be of similar reliability as the Goldmann method, is less dependent on central corneal thickness because of a smaller area of applanation. ${ }^{3}$ In addition, a portable system can be used independent from the patient's pose, which makes it particular useful for our present investigation.

Recently, Teng et al postulated that a tight necktie might be a risk factor for increased IOP. ${ }^{4}$ The aim of our study was to determine whether the latter is dependent on different poses of the examined subject.

\section{SUBJECTS AND METHODS}

Twenty six subjects (14 male, 12 female) without diagnosis or family history of open angle glaucoma were enrolled in this prospective, observational trial. Each participant has given written informed consent before inclusion in the study and underwent complete ophthalmological examination, including best corrected visual acuity (BCVA), slit lamp examination, Goldmann applanation tonometry, and fundu- scopy with careful optic nerve head examination. In addition, body mass index (BMI) and neck circumference (NC) were evaluated. Three individuals were excluded because of probable glaucomatous changes of the optic disc. None of the eventually included participants had BCVA less than 20/ 40, IOP readings higher than $20 \mathrm{~mm} \mathrm{Hg}$, or any other ocular disorder that might be associated with glaucoma.

Study IOP measurements of the right eye (study eye) were taken by TonoPen applanation tonometry under four different conditions: with open collar upright (A) and with the head on the headrest of the slit lamp (B), with a tight necktie upright (C) and in slit lamp position (D). Measurements with open collars were done first, followed by IOP readings with tightened neckties. The latter assessments were performed with the necktie tightened around the closed collar" to the point of slight discomfort," as proposed by Teng et al. ${ }^{4}$

For study measurements, subjects were seated in an examination chair. One drop of oxybuprocaine was instilled in the eye 3 minutes before the first tonometry. IOP was measured three times in primary gaze by the same masked examiner. Participants were allowed to blink between each individual measurement to prevent significant dehydration based variations of central corneal thickness. Successive measurements were performed 3 minutes after the participants had changed their positions. An independent reader recorded all the results and mean IOP values were calculated. To prevent bias, the TonoPen was recalibrated after each single alteration of the participant's pose.

The results were statistically analysed using SPSS 11.0 software for Windows (SPSS Inc, Chicago, IL, USA). Differences between IOP measurements in altered poses with and without necktie were put through paired samples $t$ tests. Sex subjected divergences in IOP calculations were analysed by the independent samples $t$ test. Pearson correlation coefficients were evaluated to analyse relations between IOP values and sex, BMI, or NC. We considered a $\mathrm{p}$ value of less than 0.05 statistically significant.

\section{RESULTS}

Twenty three right eyes of 23 normal subjects with a mean age of 21 (range 19-25) years participated in the study. Twelve participants were male and 11 female. Mean BMI was 23.99 (SD 2.39) and mean NC measured 362.4 (SD 23.9) $\mathrm{mm}$. Mean IOP readings were 16.9 ( $\mathrm{SD} 2.3$ ) $\mathrm{mm} \mathrm{Hg}(\mathrm{A}), 18.1$ (SD 3.0) $\mathrm{mm} \mathrm{Hg}$ (B), 17.9 (SD 2.9) $\mathrm{mm} \mathrm{Hg}$ (C), and 18.7 (SD 2.7) $\mathrm{mm} \mathrm{Hg}(\mathrm{D})$. There was no significant correlation between the participants' sex and IOP readings in either position $\left(r^{2}=0.094 \quad(\mathrm{p}=0.67) \quad(\mathrm{A}), r^{2}=0.232 \quad(\mathrm{p}=0.29) \quad(\mathrm{B})\right.$, $r^{2}=0.095(\mathrm{p}=0.67)(\mathrm{C})$, and $\left.r^{2}=0.192(\mathrm{p}=0.38)(\mathrm{D})\right)$. In addition, neither BMI nor NC was significantly correlated with IOP measurements in any of the four poses.

Abbreviations: $\mathrm{BCVA}$, best corrected visual acuity; BMl, body mass index; IOP, intraocular pressure; NC, neck circumference 
Table 1 Mean IOP changes maintained by the participants' poses

\begin{tabular}{|c|c|c|c|c|}
\hline \multirow[b]{2}{*}{ Pose variants } & \multirow[b]{2}{*}{ Mean (SD) $(\mathrm{mm} \mathrm{Hg})$} & \multicolumn{2}{|l|}{$95 \% \mathrm{Cl}$} & \multirow{2}{*}{$\begin{array}{l}\text { p Value (paired } \\
\text { samples } t \text { test) }\end{array}$} \\
\hline & & LL (mm Hg) & $\mathrm{UL}(\mathrm{mm} \mathrm{Hg})$ & \\
\hline$A \vee B$ & $1.25(2.56)$ & +0.15 & +2.36 & 0.028 \\
\hline$C \vee D$ & $0.84(2.74)$ & -0.35 & +2.03 & 0.156 (NS) \\
\hline$A \vee C$ & $1.04(2.56)$ & -0.06 & +2.15 & 0.063 (NS) \\
\hline$B \vee D$ & $0.63(3.15)$ & -0.73 & +1.99 & 0.348 (NS) \\
\hline
\end{tabular}

Table 1 shows details about IOP changes between the different poses of the participants. IOP increased significantly when subjects had moved from (A) to (B) $(p=0.028)$. No significant difference appeared, when people changed from position (C) to (D) or between (B) and (D). There was a trend towards higher IOP if the participants wore tight neckties; however, this divergence was not statistically significant for any pose.

\section{DISCUSSION}

Broad information about significant risk factors for IOP elevation will facilitate the identification of subjects threatened by glaucoma. ${ }^{1}$ Within the scope of accurate IOP measurement, tight neckties have recently been blamed for inaccurate results of IOP calculation, thus being a risk factor for glaucoma. ${ }^{4}$

In the present study, we have evaluated IOP in two different poses under two diverse circumstances. The IOP of all participants, firstly, was measured in a comfortably seated, "daily life" position and, secondly, in slit lamp position as common in an ophthalmologist's office. Both poses were evaluated with and without constricting necktie.

We found a significant increase of mean IOP when normal subjects with open collars changed from erect to slit lamp position. However, this was not true when the participants wore tight neckties. We did not find significant IOP alterations in slit lamp position with or without a necktie. There was a trend to higher IOP if subjects wore tight neckties in an upright position; however, we were unable to find significant differences between open collars and astringent necktie measurements in any pose.

Congestion of episcleral veins as a result of constriction of the craniocervical blood flow can cause a significant IOP rise. ${ }^{5}$ For comprehensive glaucoma care one has to consider various aspects of daily life as possibly increasing IOP. Of these, tight neckties have been proposed to be a risk factor for the development of glaucoma. In detail, men with thick necks, white collar professionals and men who prefer to wear tight neckties were considered to be endangered by increased IOP. ${ }^{4}$ Following this hypothesis, a considerable number of individuals in the industrialised world would be at risk for the development of glaucoma. However, the results of our present study do not suggest that astringent neckties are to be blamed for significant IOP increase. Furthermore, NC or BMI did not have impact on our IOP measurements with or without neck constriction. Hence it remains doubtful if tight neckties have to be considered as a risk factor for glaucoma.

Besides aspects of the patient's daily life, one has to look carefully at what may compromise correct IOP evaluation in the ophthalmologist's office. When IOP is measured at the slit lamp by applanation tonometry, the patient will not be seated comfortably upright but slightly bent forward with the neck retroflexed. This may lead to internal constriction of the jugular vein, consequently causing elevation of intracranial blood pressure. ${ }^{6}$ Subsequent IOP elevation might then occur as a result of increased episcleral venous pressure. In accordance, we found a significant IOP increase when participants with open collars changed from an upright to a slit lamp position. To what extent blood flow physiology is altered under the latter circumstances is not known.

In summary, neck retroflection can cause significantly increased IOP measurements in healthy subjects independent from BMI or NC. Consequently, applanation tonometry in the slit lamp position may not accurately reproduce IOP levels under everyday circumstances. In contrast with other investigators, we cannot confirm that tight neckties have a considerable impact on diagnosis and management of glaucoma.

\section{Authors' affiliations}

T Theelen*, C F M Meulendiiks*, D E M Geurts, A van Leeuwen,

N B M Voet, A F Deutman, Department of Ophthalmology, University Medical Centre Nijmegen, Nijmegen, Netherlands

*The authors wish to be known that, in their opinion, the first two authors should be regarded as joint first authors.

The authors have no proprietary or financial interest in this study.

Presented in part as a poster at the 198th meeting of the Dutch Opthalmologic Society, Amsterdam, Netherlands, March 2004, and at the congress of the European Glaucoma Society, Florence, Italy, June 2004 .

Correspondence to: Thomas Theelen, MD, Department of Ophthalmology, University Medical Centre Nijmegen, Philips van Leijdenlaan 15, 6525 EX Nijmegen, Netherlands; t.theelen@ohk.umcn. $\mathrm{nl}$

Accepted for publication 14 June 2004

\section{REFERENCES}

1 American Academy of Ophthalmology. Intraocular pressure and aqueous humor dynamics. In: Liesegang TJ, Deutsch TA, Grand MG, eds. Basic and clinical science course. Section 10: Glaucoma. San Francisco: American Academy of Ophthalmology, 2003:14-24.

2 Emara BY, Tingey DP, Probst LE, et al. Central corneal thickness in low-tension glaucoma. Can J Ophthalmol 1999;34:319-24.

3 Viestenz A, Lausen B, Junemann AM, et al. Comparison of precision of the TonoPenXL with the Goldmann and Draeger applanation tonometer in a sitting and recumbent position of the patients - a clinical study on 251 eyes. Klin Monatsbl Augenheilkd 2002;219:785-90.

4 Teng C, Gurses-Ozden R, Liebmann JM, et al. Effect of a tight necktie on intraocular pressure. Br J Ophthalmol 2003;87:946-8.

5 Sultan M, Blondeau P. Episcleral venous pressure in younger and older subjects in the sitting and supine positions. J Glaucoma 2003;12:370-3.

6 Mavrocordatos $\mathrm{P}$, Bissonnette $B$, Ravussin P. Effects of neck position and head elevation on intracranial pressure in anaesthetized neurosurgical patients preliminary results. J Neurosurg Anesthesiol 2000;12:10-14.

7 Toole JF. Effects of change of head limb and body position on cephalic circulation. N Engl J Med 1968;279:307-11. 